\title{
Computer learning evaluation with pre-test and post-test in preclinical education
}

\author{
Phakakrong Samrejrongroj ${ }^{1}$, Anchern Krikongjit ${ }^{2}$, Nitchatorn Sungsirin $^{3}$, Vanich Vanapruks ${ }^{4}$
}

\begin{abstract}
Background: Pre-test and post-test have been popularly managed in various designs in Medical Education. Tests for basic computer were performed digitally during 2004 to 2007 at Phramongkutklao College of Medicine, Thailand.

Objective: To find the effectiveness of the digital pre-tests and post-tests as a tool in computer learning evaluation and course assessment for Preclinical education.

Methods: Three contents of multiple choice questions were performed as pre and post-tests by the medical cadets: content I in 2004 created by using the Tool book II Instructor program, content II in 2005 and III in 2006 and 2007 operated by the Moodle program. Content II and III were accessed via intranet. The outcome data were analyzed with descriptive statistics and the two-sample Z test for comparison.
\end{abstract}

Results: Each year study revealed significant higher scores in post-test than in pre-test at $p<0.05$. Both pre-test and post-test average scores in 2007 were significantly higher than in 2006 at $p<0.05$. The largest percentage number of students was conducted yearly in Fair group for pre-test and in Good group for post-test.

Conclusions: The students gained computer knowledge after finishing the course. Content II and III tests are satisfied to be used via intranet as an effective tool for the computer learning evaluation and assessment methodology of the course. Simple analysis techniques, evaluation software implementation with automatically checking and paperless score saving are the benefits of this study.

Keywords: digital pre-tests and post-tests, assessment methodology, computer learning evaluation, Preclinical education

\section{Introduction}

Computer-based learning has become a tool either as an aid to or as a replacement for traditional teaching methods and the applications

\footnotetext{
${ }^{1}$ Assistant Professor Colonel,

Phramongkutklao College of Medicine,

Bangkok, Thailand

${ }^{2}$ Lieutenant Colonel,

Royal Thai Army Medical Department

Bangkok, Thailand

${ }^{3}$ Secondary Lieutenant,

Pramongkutklao College of Medicine,

Bangkok, Thailand

${ }^{4}$ Professor Emeritus Major General

Dean, Institute of Medicine

Suranaree University of Technology

NakornRachasima, 30000, Thailand

Corresponding author:

Assistant Professor Colonel Phakakrong Samrejrongroj

109 Ramkamkaeng Soi 48, Ramkamkaeng St.

Bangkapi District, Bangkok 10240, Thailand.

Email: pkkrong@gmail.com
}

are now parts of modern medical curricula all over the world (Ruiz et al., 2006). Survey data (Lowerison, G. et al, 2006) from 22 students in 51 courses at both graduate and undergraduate levels indicated that students valued the use of computer technology for learning and favored the facilitation of learning. The study of Jotkowitz, AB (2004) pointed out Information Technology (IT) practice or IT skills were least practiced included especially spread sheets $(50 \%)$, database $(67 \%)$, presenting information orally about $50 \%$ and over $30 \%$ lacked experience in evaluating their own strengths and weaknesses. About $8 \%$ never used word processing and e-mail and $20 \%$ were unfamiliar with using the Internet. To monitor the progress of the students' learning, the pretest and post-test have been administered in many designs (Cook et al., 2004). Interestingly, Freeman et al., (2010) concluded that it was advancing and there should be a scope for online delivery of progress tests. However, there were significant implications for summative assessment which had to be taken 
into account. Wittmann, (2010) informed the American Red Cross and American Heart Association had post-tests which students were required to pass in order to obtain the Basic Life Support (BLS) certification. In addition, a pre-test, was administered to give the students an idea of what they are going to learn and prepare them for the post-test.

The computer courses at Phramongkutklao College of Medicine (PCM) in Thailand have been improved enormously since January 10 , 1966 (The Phramongkutklao Information Center, PIC was established). From 2004 to 2007 , the PIC provided varieties of information system facilities for medical cadets and the staffs of PCM and to keep the device maintenance. At that time there were four training rooms with 30-40 network computers and in 2007, 50 computers with relevant devices including software for computer assisted instruction (CAI) and resources such as Internet/intranet, CD-Rom, files in diskettes and IT paper documents.

The computer courses for the second year medical cadets from 2004 to 2007 were in Block: Introduction to Problem Based Learning (PBL). The courses were completed within one week of the first semester. Lectures and demonstrations by the instructors, student practices and some web-based learning were conducted in class. The topics included Introduction to Operating systems, Word, PowerPoint, Excel and Network. The checklist results observed by the instructors and the assignment work considered as satisfied or unsatisfied, no grades were assigned. The scores of the pre-test and post-test were complimentary to evaluate the course (Figure 1) with the paper evaluation questionnaires which were distributed to both students and instructors but were not included in the results of this study.

The objective of this study is to find out the effectiveness and the outcome benefit of the pre-test and post-test via intranet as a tool in Computer learning evaluation and course assessment for Preclinical education.

\section{Meterials}

Participants: The second year medical cadets from 2004 to 2007 academic years of PCM who attended the computer class, Block: Introduction to PBL.
Computers: 40-50 personal computers with network system at PIC were provided to 30 medical cadets in 2004. Student per computer was 1:1. There were 65 medical cadets in 2005 and 100 medical cadets in 2006 and 2007.

\section{Software:}

(1) Moodle program, version (v.) 1.4

(2) Tool book II Instructor program, v.5

\section{Methods}

All medical cadets took the pre-tests to access their basic knowledge of computers prior to taking the computer courses and post-tests after the completion of the courses (Figure 1). In 2004, the test contained 20 multiple choice questions (MCQs) with four options given in the Tool book II Instructor Program which possessed of an evaluation program: automatically checking, the sum of the scores and time recording as well as is to print students' score immediately after completing the tests. The MCQ type which is the most popular type and high recommended validity was selected to build the tests. The test contents covered all topics of the course and were developed from computer paper test built by Prompong Peeraboon to become a digital test form by Phakakrong Samrejrongroj. The students conducted the tests on a PCM computer and the records of each test were saved for further analysis. In 2005, Phakakrong Samrejrongroj adapted the former MCQ test contents (Content I) then modified them to 25 questions by using the Moodle program which was posted on the Intranet of PCM (Content II). In 2006 academic year, Phakakrong Samrejrongroj and Anchern Krikongjit updated a few of the tests content through the Moodle program (Content III). Students must have an account and password to access the intranet test and finish the test within 10 minutes. The teacher could access the response checking, the scores and time taken by each student as well as the test analysis. This study used the reliability (KuderRichardson formula 21, KR-21) to measure the pre-tests From 2004 to 2007 (rtt, $2004=0.41$, rtt, $2005=0.74$, rtt, $2006=0.42$ and rtt, 2007 $=0.23$ ). Standard Errors of Measurement (SEm), (Tighe et al., 2010) found to be 10.84, 9.64, 9.34 and 9.17 respectively. Relative Standard Error (RSE), Wikipedia (2010) resulted was $18.48 \%, 13.80 \%, 14.18 \%$ and $13.18 \%$ respectively. 


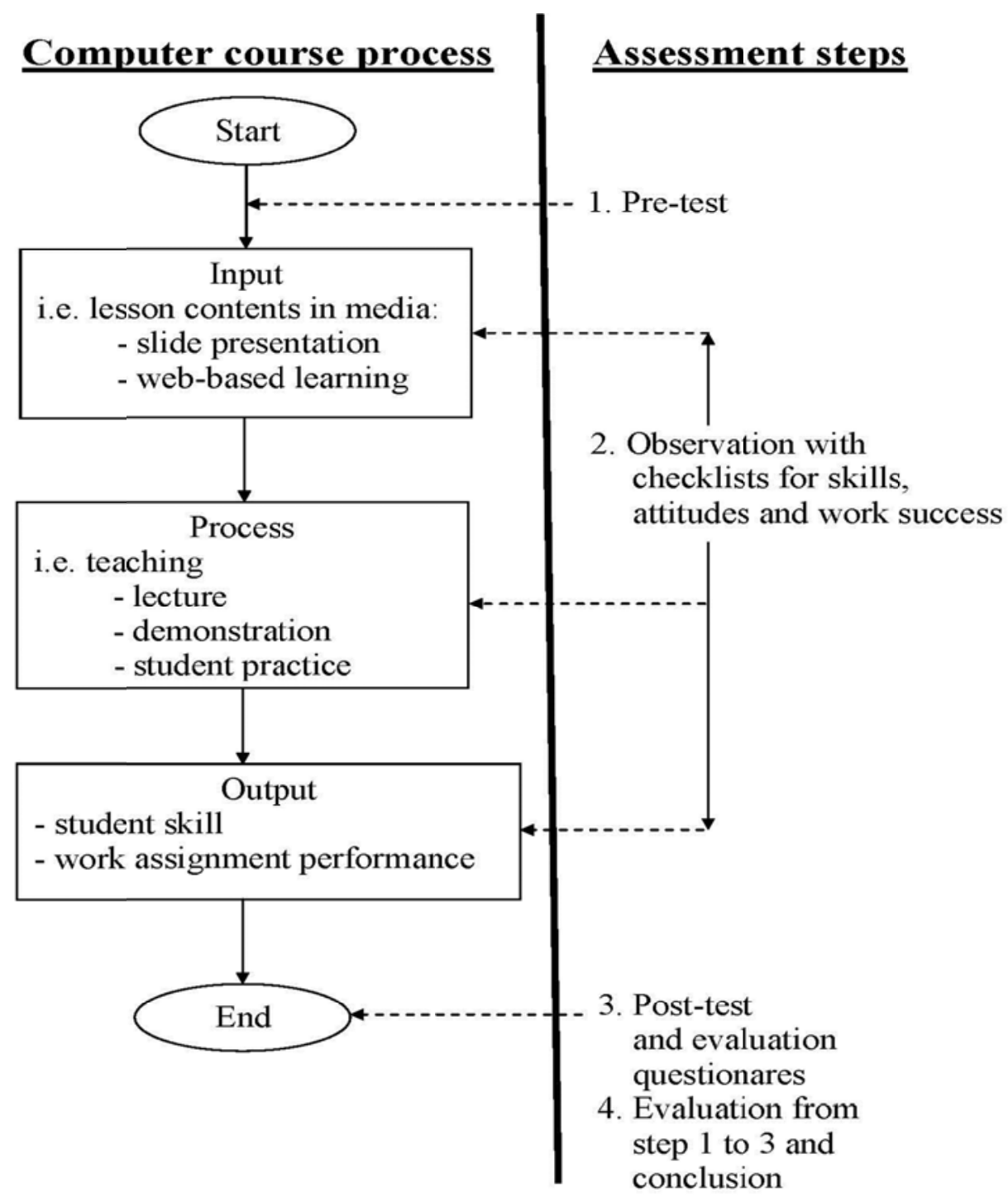

\section{Data Analysis}

Descriptive statistics e.g. means, standard deviations (SD), frequencies, and percentages were used to identify learners' characteristics. Sample $Z$ test with $p<0.05$ was used to conduct significant test for comparison.

\section{Result}

Figure 2, the pre-test and post-test scores of 30 medical cadets in 2004, 51 in 2005, 87 in 2006 and 98 in 2007 were collected for analysis. From 2004 to 2007, students scored significantly higher in the post-test than in the pre-test at $p<0.05$. In 2005 (Test Content II), two students scored $100 \%$ on pre-test, the mean \pm SD was $69.88 \pm 16.90 \%$ and one student scored $0 \%$. In 2005 post-test, the maximum was $100 \%$ by five students and the mean \pm SD raised up to $83.06 \pm 12.79 \%$ as well as the minimum was up to $52 \%$ by one student. After test content adaptation, the average scores of the same pre-test (Content III) in 2006 and 2007 resulted as $65.84 \pm 12.26$ and $69.59 \pm 10.45$ and for the post-test as $80.14 \pm 11.87$ and $83.39 \pm 10.18$ respectively. These appeared slightly different but statistically pre-test and post-test analysis revealed students scored significantly higher in 2007 than in 2006 at $p<0.05$. However, in 2006 , only one student got $100 \%$ on the pretest while in 2007 four students scored a maximum of $88 \%$. 
Figure 2: Chart comparison between pre-test and post-test scores (\%) showing average scores \pm SD, maximum and minimum scores in academic years 2004-2007.

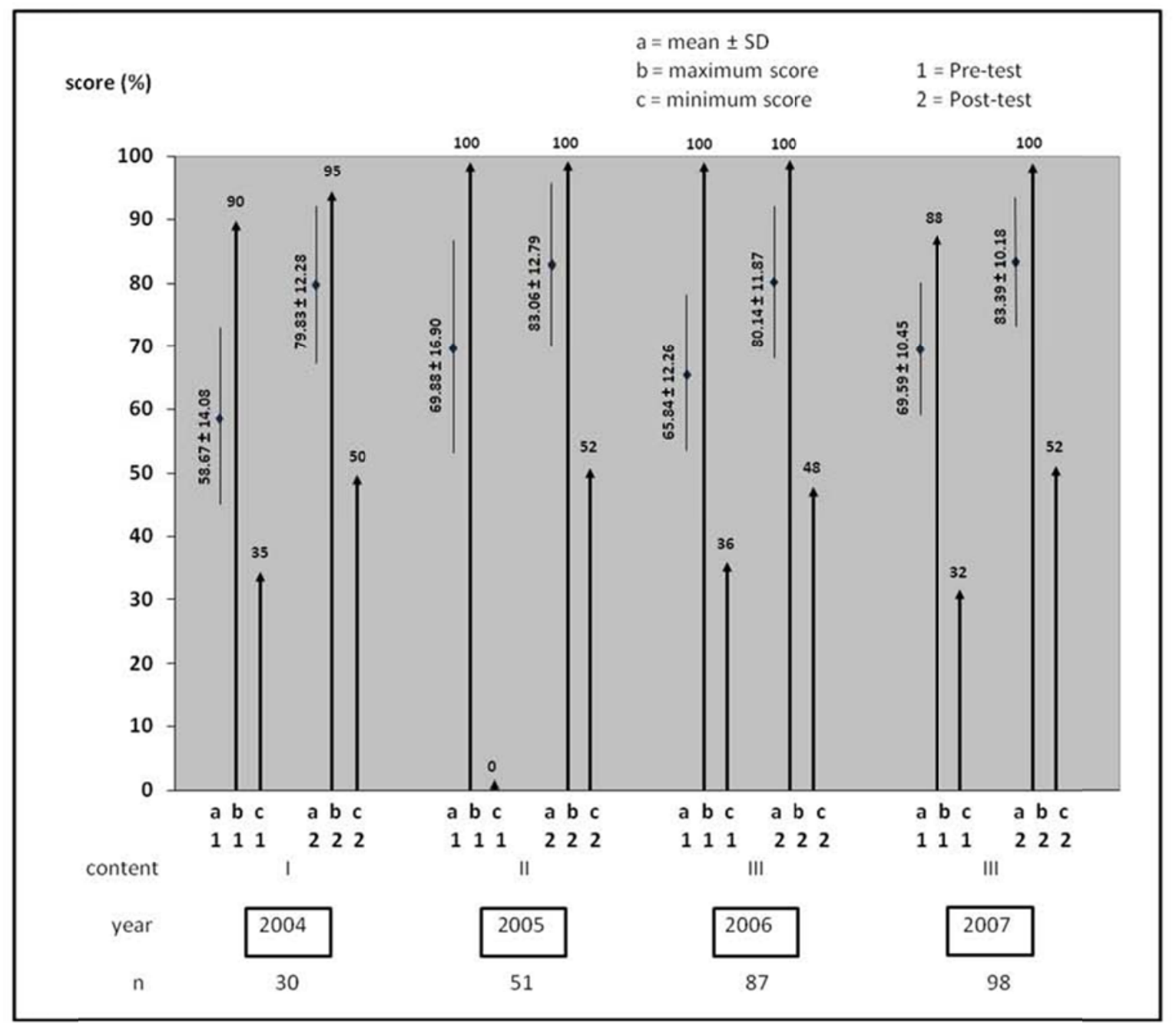

Figure 3 illustrates the number of learners classified yearly (2004-2007) into three groups by rating the score percentage: good group $(\geq$ $80 \%)$, fair group (51-79 \%), weak group ( $\leq 50$ $\%)$. Each year, the percentage increase from the weak group and fair group to a good group was observed in post-test. In the post-test studied, only small percentages were in the weak group (0-3.33\%). It was also observed the largest number of students scoring on the pre-test was in the fair group and on the posttest was in the good group. The highest percentage students in the good group was in 2005 for the pre-test and 2007 for the posttest. The lowest percentage in the weak group was in 2007 for both the pre-test and post-test and in 2005 for the post-test. In 2006, the percentage of the weak group dropped significantly from $10.34 \%$,the pre-test to 1.15 $\%$, the post-test of the good increased from $16.09 \%$ to $60.91 \%$ and the fair group post-test was 2 times lesser than in the pre-test. In 2007, the results were similar. The weak group on the pre-test was $3.06 \%$ and on the posttest was none. The percentage changed in the good group in 2007 pre-test was higher than in 2006 about $4.32 \%$ and the weak group was lesser than $6.28 \%$. In post-tests, the number of students from the good group in 2007 was more than in 2006 about $12.56 \%$ and the weak group was still found $1.15 \%$ in 2006 . 
Figure 3: A bar chart showing the number of medical cadets whose scores were classified into three groups of rating (good, fair and weak) in 2004-2007

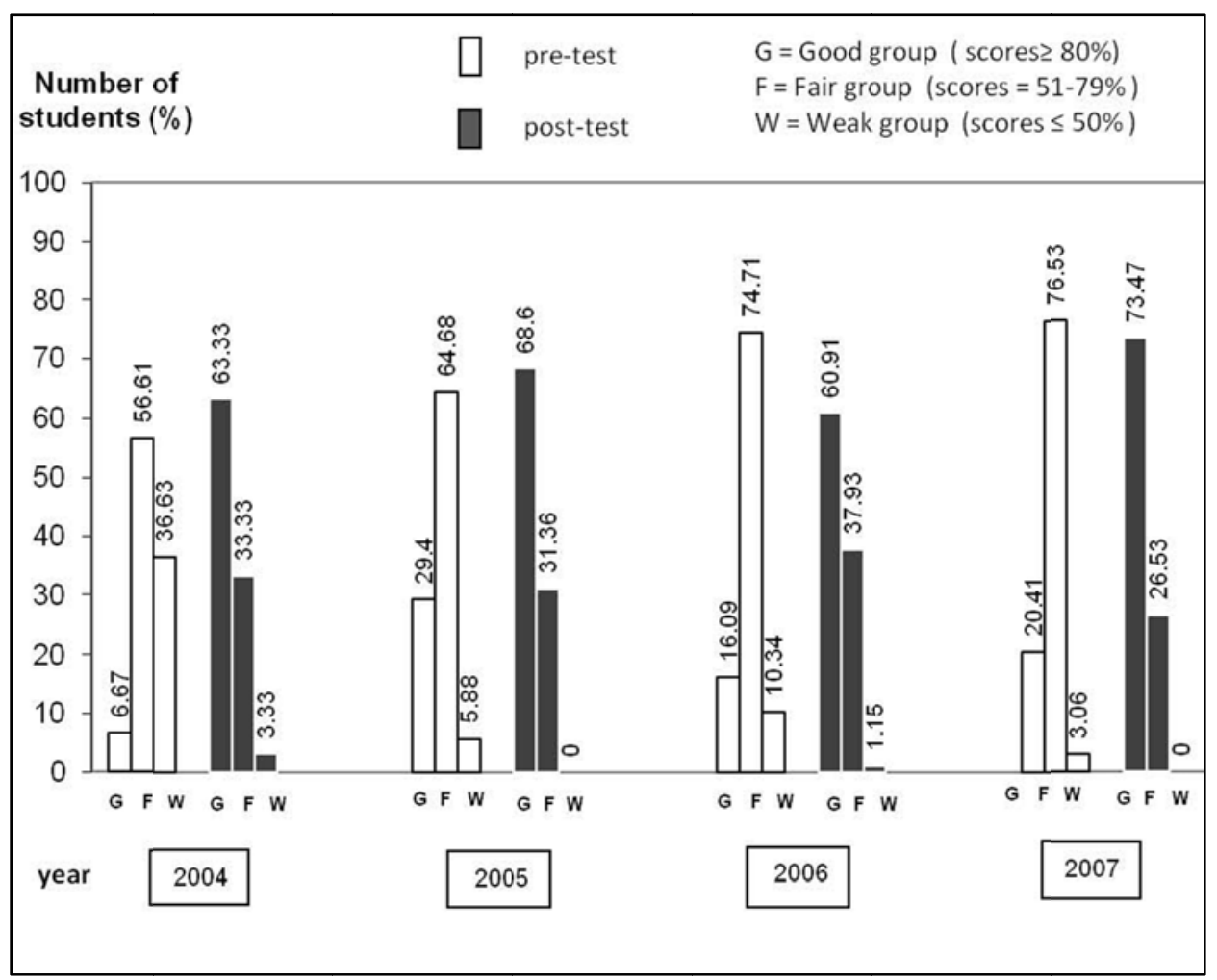

\section{Discussion}

Test results in this study supported medical cadets trend to have more basic computer knowledge than previous years. We think that this is due to the world of information technology advancing and the student computer accessories available to access the knowledge by self-study through the internet. In addition, the results from Figure 2 revealed the medical cadets gained more knowledge of computers after finishing the course. Although the learners took the same or different tests the average scores of the post-tests in this study were satisfied as they ranged between $79.83 \pm 12.28$ and $83.39 \pm 10.18$. Currently, technology globalization has changed rapidly, more information technology systems have been provided such as services, equipment's, training courses and trainers. These effect medical education. Since the teaching time in preclinical education is less constraint than in clinical education and is also the preliminary course of medical teaching in PCM, a basic computer course ought to be placed in the curriculum. Next, the management of a computer course should be offered yearly to achieve the medical education objective. Subjects in pre-clinical education such as microbiology, anatomy, biochemistry and physiology which managed wet laboratories can in the future similar to other institutions use web-based learning and computer assisted instruction (CAI) as (Kröncke, 2010). The digital pre-test and post-test would be useful for course evaluation. Reminding that the contents of the pre-test seem to be the guideline for students to prepare themselves for the subject. The Moodle program via intranet used in this study which is free is recommended instructors to build the MCQ test. With regard to the ease of this program usage, convenient updlate contents, cost saving and faster access to the intranet than to the internet are also the reasons. Moreover, the test contents should be developed to be more advanced or problem-based. The high reliability test $(\mathrm{K}-\mathrm{R} \mathrm{21}$, rtt $=0.74)$ in this study was in Content II, 2005 but their SEm and RSE revealed that Content III, 2007 seemed to be more reliable than the others in this study. The SEm was mentioned in the Technical Assistance Paper, 1996 that the larger the SEm, the lesser the reliability of the test and it was stated by Tighe et al., (2010) that the SEm was a more appropriate measure of quality for postgraduate medical assessments 
than is reliability. Wikipedia, (2010) noted that the US National Center for Health Statistics typically did not report an estimate if the RSE exceeds $30 \%$. All RSE in this study are between $13.18 \%-18.48 \%$ which is lesser than the maximum limited. According to Carey, (2010), - "in recent years, cognitive scientists shown that a few simple techniques can reliably improve what matter most: How much a student learns from studying?", This might decrease the teacher's tension in forming the high reliability test. However, pre-test and post-test for computer training is still to be a tool to assess the basic knowledge of trainees with other effective tools in order to have the appropriate course management and to meet the objectives of the preclinical education. The study of Masiello et al., (2005) focused on the readiness and attitudes of students to take online microbiology courses is interesting. They informed that on average the students mastered the pre-requisite ICT competences and expressed positive attitudes towards the system to use it flexibly. The implementation of learning online in medical education with these achievement tests through the institution learning repositories also considered on feasibility of the significant learning gained. For students experiences and skills, modern features and competency of both computer hardware and software should be included in class.

\section{Conclusion}

The students gained knowledge in the computer class. The pre-test and post-test are important tools for teaching and learning assessment in preclinical education and better performed via intranet. Assessment motivates students in their studies and measures the effectiveness of training and identifies curriculum weaknesses. The MCQ test Contents II and III in this study are more reliable than Content I. However, they provide the meaningful and trustworthy data and interpretation as proved by RSE indicator. Other tools such as the checklist for student performance and success of the assignment work are the main criteria for passing the course. Course evaluations of these study groups are quite successful along with software implementation via the intranet and paperless score are simple analysis techniques.

\section{Acknowledgements}

The authors conducted this study as an assessment methodology research and finished successfully with the co-operation of the medical cadets who attended the computer course, the staff of Phramongkutklao Information Center, Phramongkutklao College of Medicine who prepared the hardware, the software and documents for the course. We also thank Associate Professor Major General Preyapan Sangaroon, the Educational Dean of Phramongkutklao College of Medicine, for her encouragement and Emeritus Professor Major General Vanich Vanapruks for her advice.

\section{References}

Bishop, D. (1996) Standard Error of Measurement. In: Technical Assistance Paper, Valid issue Feb 1996. Paper number: FY 1996-7

Carey, B. (2010) Truth about effective approaches to learning. Bangkok Post. Oct 5, 2010. p. 08

Cook, D.A. \& Dupras, D.M. (2004) Teaching on the Web: Automated online instruction and assessment of residents in an acute care clinic. Med teach, 26 (7), pp. 599 - 603.

Freeman, A.C. \& Ricketts, C.(2010) Choosing and designing knowledge assessment Experience at a new medical school. Med teach 32, pp. 578-581.

Jotkowitz, A.B., Gaasearud, A., Gidran, Y., Urkin, J., Margolis, C. Z \& Henkin, Y. (2004) Evaluation of student attitudes and knowledge in a new program in international health and medicine. Med Teach, 26 (6), pp. 574-578.

Kröncke, K.D. (2010) Computer-based learning versus practical course in pre-clinical education: Acceptance and knowledge retention. Med Teach, 32, pp. 408-413.

Ruiz, J.G., Mintzer, M.J. \& Leipzig, R.M. (2006) The impact of e-learning in medical education. Acad Med, 81, pp. 207-212.

Lowerison, G., Sclater, J., Schmid, R.F. \&Abrami, P.C. (2006) Student perceived effectiveness of computer technology use in post-secondary classrooms. Computer \& Education, 47, pp. 465-489.

Masiello, I., Ramberg, R. \& Lonka, K. (2005) Attitudes to the application of a Web based learning system in a microbiology course, Computers \& Education, 45, pp. 171 - 185.

Tighe, J., McManus, I.C., Dewhurst, N.G., Chis, L.\&Mucklow, J.( 2010) The Standard Error of Measurement is a more appropriate measure of quality for postgraduate medical assessments than is reliability: an analysis of MRCP (UK) examinations. BMC Medical Education, pp.10: 40. Online, http://www.bio medcentral.com/1472 - 6920/10/40.

Wittman, L. (2010) How to study for the Basic Life Support Pre-test and Post-test. [Online]. Available at: http: //www.ehow.com, [Accessed Dec 22, 2010]. 